\title{
Characterization of PZT/PVDF Composite Film as Functional Material
}

\author{
Ricardo Luiz Barros de Freitas ${ }^{(0)}$, Walter Katsumi Sakamoto, Luciana Paro Scarin Freitas, Fabian Castro ${ }^{\circledR}$, \\ Antonio P. Lima Filho, Claudio Kitano, and Aparecido Augusto de Carvalho ${ }^{(0)}$
}

\begin{abstract}
In this paper, we obtained and characterized a composite film made of lead zirconate titanate (PZT) piezoelectric ceramic and nonpolar polyvinylidene fluoride ( $\alpha$-PVDF) as a functional material. The scanning electron microscopy results show this composite film to have mixed connectivity due to the agglomeration of some of the PZT particles. The response of the composite to an applied ac voltage at $4110 \mathrm{~Hz}$ has a slope of $0.074 \mathrm{~nm} / \mathrm{V}$. The measured displacement is in the range of 0-30 nm for electric voltages ranging from 0 to $400 \mathrm{~V}$. The experimental results show the composite performance as an acoustic emission sensor to be in good agreement with the response of a commercial standard microphone in the frequency range of 2-6 kHz. By applying $2 \mathrm{kN}$ of cyclic force at a frequency of $3 \mathrm{~Hz}$, we obtained an $80-\mathrm{V}$ peak signal and calculated a dissipated power equal to $158 \mu \mathrm{W}$.
\end{abstract}

Index Terms-Lead zirconate titanate (PZT), non-polar polyvinylidene fluoride ( $\alpha$-PVDF).

\section{INTRODUCTION}

$\mathbf{T}$ ODAY, functional materials are the target of much multidisciplinary research toward the development of a new material that can perform a number of specific engineering functions. Although Thomas [1] suggested that any material could be designated as functional, the goal here is to obtain a truly smart material, that can be used as both a sensor and actuator at the same time.

In this regard, several studies have been conducted and different kind of materials used, such as polymers, fiber composites, and metallic foams, depending on the application. The main objective is to integrate the actuation mechanism that controls the structural motion with the sensing mechanism that monitors the structure [2]-[6]. The number of papers on this subject has increased considerably with the growing interest in nanomaterials [7]-[9] and the corresponding range of applications.

Manuscript received March 20, 2018; accepted April 18, 2018. Date of publication April 25, 2018; date of current version May 22, 2018. This work was supported by the Brazilian Councils CAPES and CNPq. The work of W. K. Sakamoto was supported by the São Paulo Research Foundation FAPESP under Grant CEPID-CDMF 2013/07296-2. The associate editor coordinating the review of this paper and approving it for publication was Dr. Jürgen Kosel. (Corresponding author: Ricardo Luiz Barros de Freitas.)

R. L. B. de Freitas is with the Department of Electrical Engineering, UNIOESTE-Universidade Estadual do Oeste do Paraná, Foz do Iguaçu Campus, Foz do Iguaçu 85867-900, Brazil (e-mail: rlbfreitas@gmail.com).

W. K. Sakamoto, F. Castro, A. P. Lima Filho, C. Kitano, and A. A. de Carvalho are with UNESP-São Paulo State University, Ilha Solteira Campus, Ilha Solteira 15385-000, Brazil.

L. P. S. Freitas is with the Faculdade União das Américas, Foz do Iguaçu 85853-000, Brazil.

Digital Object Identifier 10.1109/JSEN.2018.2830115
Of the multifunctional materials, piezoelectric materials, i.e., piezoelectric ceramic and piezoelectric polymers, have important roles since they can function as both actuator and sensor materials. Several good papers published in the past decade have focused on their sensing and energy harvesting characteristics of them [10]-[14]. The study of piezoelectric materials has included ferroelectric polymers and copolymers and ferroelectric ceramics. However, for some specific applications, these may not work adequately due to their individual properties, such as the low dielectric constant in polymers and the mechanical fragility of ceramics. To overcome this problem, the ceramic/polymer composite has been developed as an alternative material that combines the properties of each single phase to yield a new material with a tailored performance as either actuating or sensing.

The use of piezoelectric materials instead of electromagnetic devices is in response to the advantages offered by piezo materials, including their suitability to miniaturization, no electromagnetic noise generation, and higher efficiency [15]. For two-phase composites consisting of an electroactive ceramic and polymer, according to Newnham et al. [16], the 0-3 connectivity pattern, i.e., " 0 " for the isolated ceramic particles dispersed into the " 3 " polymer matrix connected in all three dimensions, is the lowest in cost and easiest composite to produce of the ten possible combinations. Of course, depending on the ceramic fraction content in the composite, the sample can display a mixed connectivity $(0-3$ and $1-3)$ while maintaining its flexibility and ease of preparation.

The PZT/polymer composite has been extensively studied over the last three decades, with the main objective being improvement of the electromechanical properties of the new material. To do so, many polymer phases have been used as the matrix, in which the ceramic phase is dispersed to form the composite material. All PZT/polymer composites show increased piezoelectric activity as the ceramic content is increased. Also, the composite material has shown an enhanced piezoelectric coefficient when poled with a higher electric field [17]-[21].

Based on these results and because the focus of the present work is to demonstrate the potential of the PZT/PVDF composite film as a functional material, the results reported here are for a 50/50 vol\% composite. The sample with a $30 \mathrm{vol} \%$ of PZT yielded a low piezoelectric coefficient and that with a $70 \mathrm{vol} \%$ of PZT was brittle and broke under an applied $2 \mathrm{kN}$ force. Although we analyzed samples with only one PZT/PVDF ratio (50/50 vol\%), the results of this study 
contribute to the sensor and actuator research area since they show that an PZT/PVDF composite sample can be used as an $\mathrm{AE}$ sensor, as an actuator that produces displacement in the nanometer range, and also as a renewable source to generate clean energy.

\section{MATERIALs AND METHOD}

We obtained circular PZT/PVDF composite films $50 \mathrm{~mm}$ in diameter, and $0.5 \mathrm{~mm}$ thick by hot pressing a mixture of PZT $(\rho=7.6 \mathrm{~g} / \mathrm{cm} 3)$ and $\alpha-\operatorname{PVDF}(\rho=1.8 \mathrm{~g} / \mathrm{cm} 3)$ powders. We purchased the PZT powder from American Piezo Ceramics (APC) under reference 850. Its characteristics include a: Curie temperature of $360{ }^{\circ} \mathrm{C}$, relative dielectric constant equal to $1900(1 \mathrm{kHz})$, average particle size of $50 \mu \mathrm{m}$, and piezoelectric charge constant $\mathrm{d} 33=400 \mathrm{pC} / \mathrm{N}$. We obtained the PVDF powder from Solvay, which, according to the manufacturer, has an average grain size of around $80 \mu \mathrm{m}$. We manually mixed the powder and placed the mixture on a Kapton sheet, which we then placed in a stainless-steel die. To produce the sample, we then pressed the die with the well-mixed powders at an empirically determined pressure of $2.4 \times 10^{7} \mathrm{~Pa}$ for $1.0 \mathrm{~min}$ at $190{ }^{\circ} \mathrm{C}$, using a thermocouple to indicate the temperature. We selected the desired volume percentage of PZT and calculated the mass of the constituents using (1), as follows:

$$
M_{P Z T}=M_{P V D F} * \frac{\rho_{P Z T}}{\rho_{P V D F}} * \frac{\% P Z T}{1-\% P Z T}
$$

where, $\mathrm{M}$ is the mass, $\rho$ is the density, and \%PZT is the fraction of PZT in the composite sample.

To generate piezoelectric activity, based on [17], we poled the samples with a $10 \mathrm{MV} / \mathrm{m}$ electric field. We immersed the samples in silicone oil to prevent electrical breakdown performed poling for $1.0 \mathrm{~h}$, while maintaining the poling temperature at $90{ }^{\circ} \mathrm{C}$. To establish electrical contact, we vacuum evaporated aluminum electrodes onto both sides of each sample. A high-poling electric field is achieved due to the polymer phase in the composite film.

To characterize the PZT/PVDF 50/50 vol\% composite film and determine the particle distribution in the polymer matrix, we used a JOEL model JSM-7500F scanning electron microscop (SEM-FEG). We used energy dispersive spectroscopy (EDS) to analyze the chemical components of the composite. Figure 1 shows a block diagram of the equipment used to analyze the performance of the composite as an actuator. The optical interferometer we used is based on that used in the Michelson experiment [22].

We investigated the acoustic emission detection properties of the PZT/PVDF composite film with reference to the American Society for Testing and Materials -ASTM E97610 standard [23], as shown in Fig. 2. The pencil-lead break is a conventional and well-known test for the detection of acoustic emissions.

We also performed energy conversion tests on a system that simulates the pedestrian and automobile traffic on a track in which a composite film is embedded. To the sample, we applied a force of $2 \mathrm{kN}$ at a cyclical frequency of $3 \mathrm{~Hz}$ and

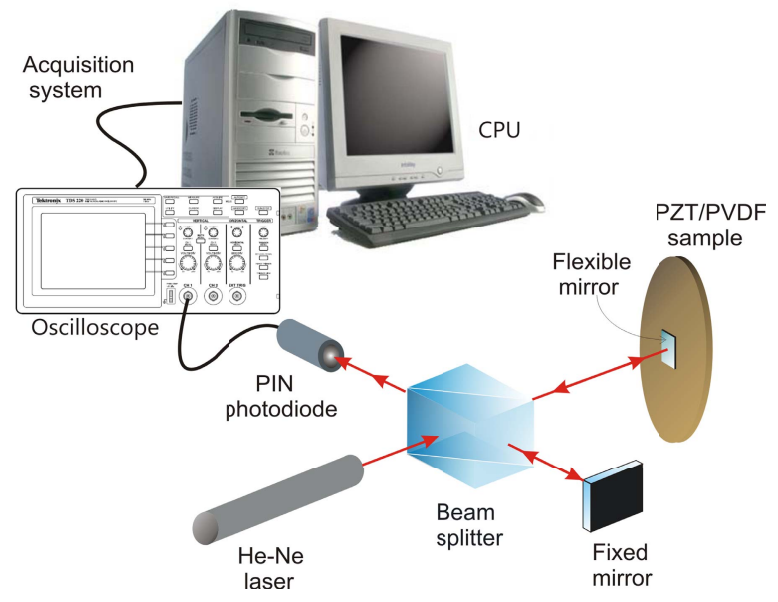

Fig. 1. Block diagram to analyze the actuator property of the composite sample.

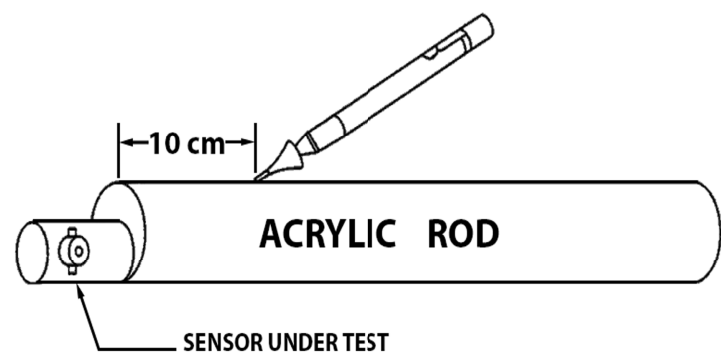

Fig. 2. Pencil-lead break test Hsu-Nielsen method.

obtained the electrical signal by observing the sample deformation on an oscilloscope. In the energy harvesting experiment, we placed the sample between two copper thin foils, which served as the electrical contact. To protect the sample, we placed this system between two aluminum plates $2.0 \mathrm{~mm}$ thick. To simulate a street on which people walk or cars travel, this apparatus uses a steel roll driven by a planer machine to apply mechanical deformation force onto the composite film. The roll was boosted onto the sample with a $2 \mathrm{kN}$ force at a frequency of $3 \mathrm{~Hz}$ and we used an oscilloscope to record the electrical signal generated by the sample (Agilent DSO6012A), as shown in Fig. 3.

\section{RESULTS AND DISCUSSION}

We analyzed a 50/50 vol\% PZT/PVDF sample $50 \mathrm{~mm}$ in diameter and $0.5 \mathrm{~mm}$ thick using (2), which was proposed by Guo et al. [24]:

$$
d_{33}=\frac{\kappa \varepsilon_{0} A V_{p}}{F t}
$$

where $\kappa$ is the relative dielectric constant, $\varepsilon_{0}=8.85 \times 10^{-12}$ is the vacuum permittivity, $A$ is the sample area, $V_{p}$ is the peak voltage, $F$ is the applied force, and $t$ is the sample thickness. We obtained the value of $72 \mathrm{pC} / \mathrm{N}$. The SEM results revealed the size of the PZT particles to range from 130-300 nm, dispersed throughout the PVDF matrix. In Fig. 4, we can see some agglomeratione of particles, which indicates mixed 


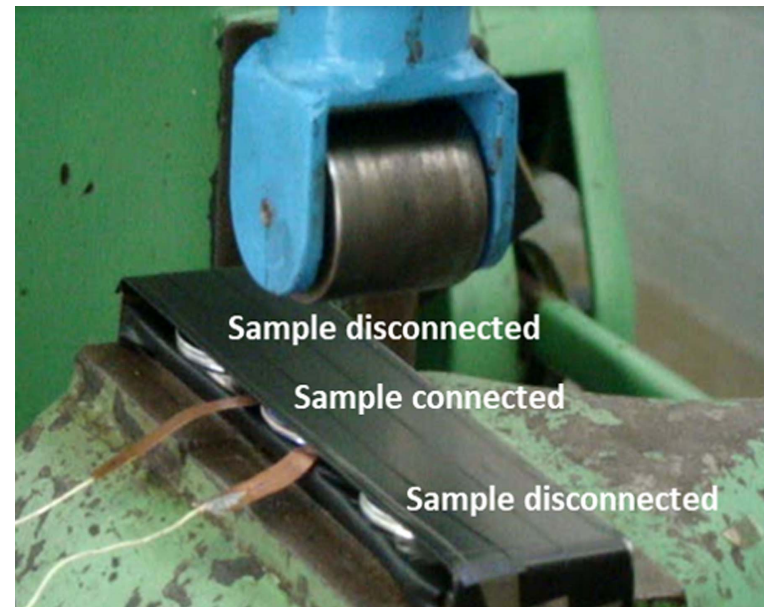

Fig. 3. Apparatus used to simulate car traffic on the composite sample to generate energy.

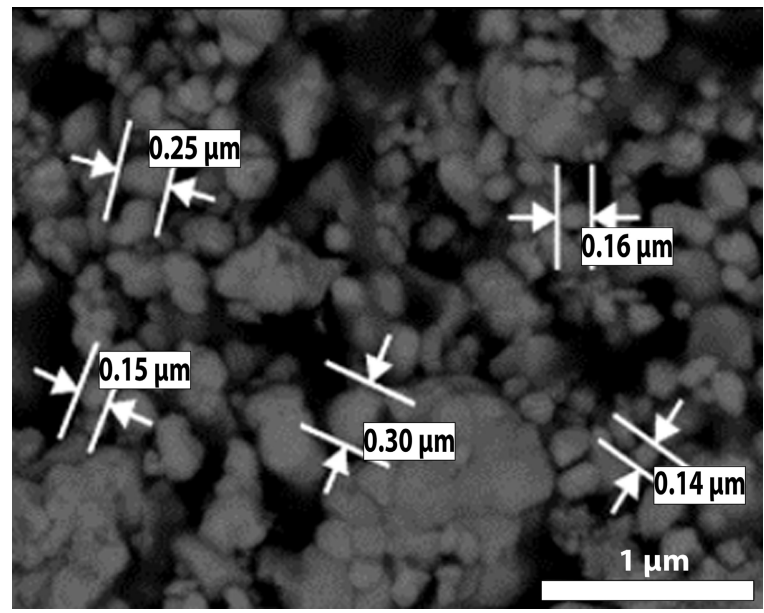

Fig. 4. Backscattering image of the fractured surface of PVDF/PZT composite.

connectivity. With 50 vol\% of PZT, the composite cannot be considered to be a pure 0-3 composite, since there is some connection between particles. The EDS analyses (Fig. 5) showed no composite contamination or chemical reaction between the individual phases. We also observed the presence of carbon in the EDS spectrum of the composite film in the pure PZT spectrum, which was thought to be due to the ITO conductive tape used to fix the sample to the holder.

Figure 6 shows the actuator performance of the composite film. We observed a linear relationship between the mechanical displacement and the applied electrical voltage. The mechanical deformation of the composite film under the applied electrical voltage is related to the inverse piezoelectric effect of the poled PZT particles, since PVDF is non-polar. We used three different frequencies: $3100 \mathrm{~Hz}, 3600 \mathrm{~Hz}$, and $4110 \mathrm{~Hz}$. The slope indicates the calibration factor of the composite as an actuator, which depends on the frequency of the applied electrical signal. At $4110 \mathrm{~Hz}$, the composite film displayed better sensitivity to deformation with $0.074 \mathrm{~nm} / \mathrm{V}$, followed by the response at $3600 \mathrm{~Hz}$ with $0.023 \mathrm{~nm} / \mathrm{V}$ and finally the composite film at $3100 \mathrm{~Hz}$ with $0.015 \mathrm{~nm} / \mathrm{V}$. We observed a small hysteresis in the higher frequency $(0.4 \mathrm{~nm})$, as shown in Fig. 7.

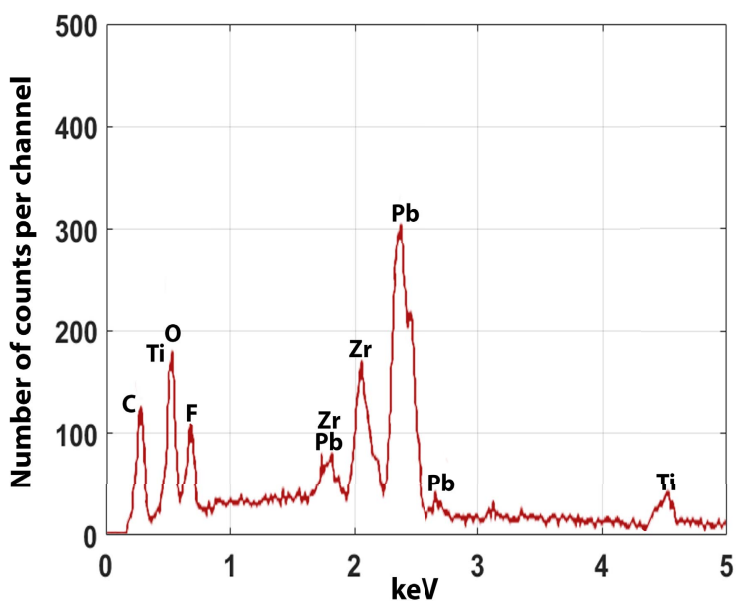

Fig. 5. EDS results for the PZT/PVDF sample.

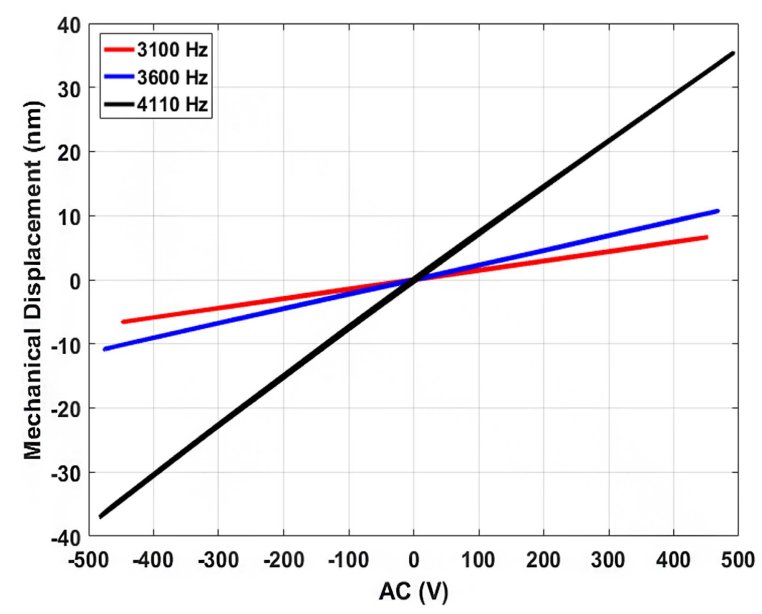

Fig. 6. Sample response to applied electric voltage.

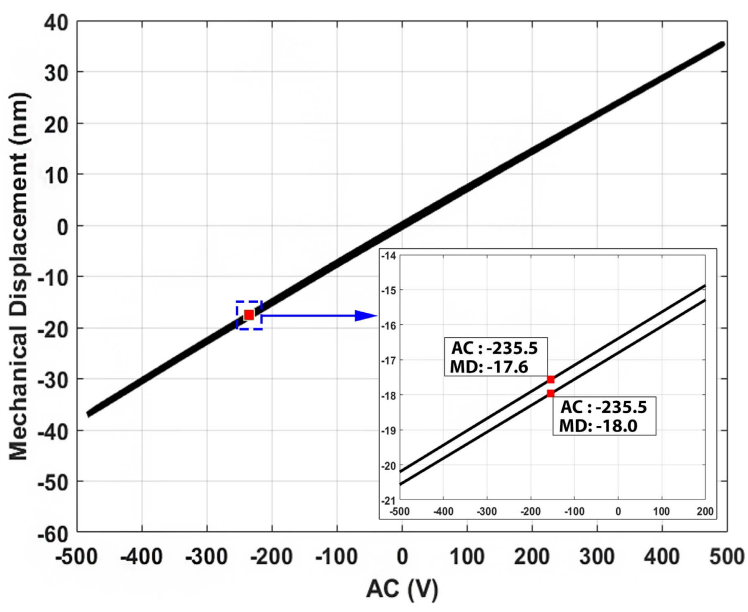

Fig. 7. Small hysteresis for $900 \mathrm{~V}$ peak-to-peak applied voltage.

To demonstrate the composites capacity for use as an acoustic emission detector, we performed a pencil-lead break experiment. In the experimental setup, shown in Fig. 2, we used the ASTM E 967-10 standard. Following the wellknown Hsu-Nielsen experiment [25], we broke the pencil lead $10 \mathrm{~cm}$ from the sensor.

Figure 8 shows the sensor response as a function of time. In the test, we eliminated the DC component of the signal and 


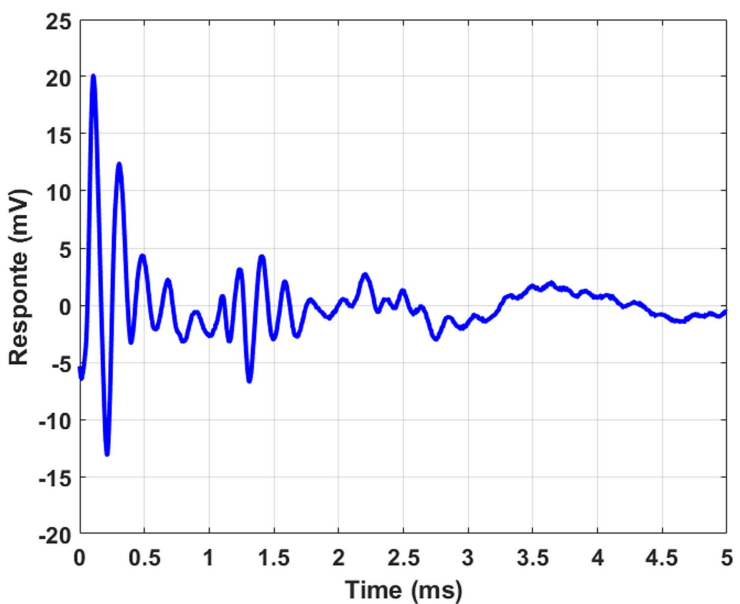

Fig. 8. AE Sensor response in the time domain.

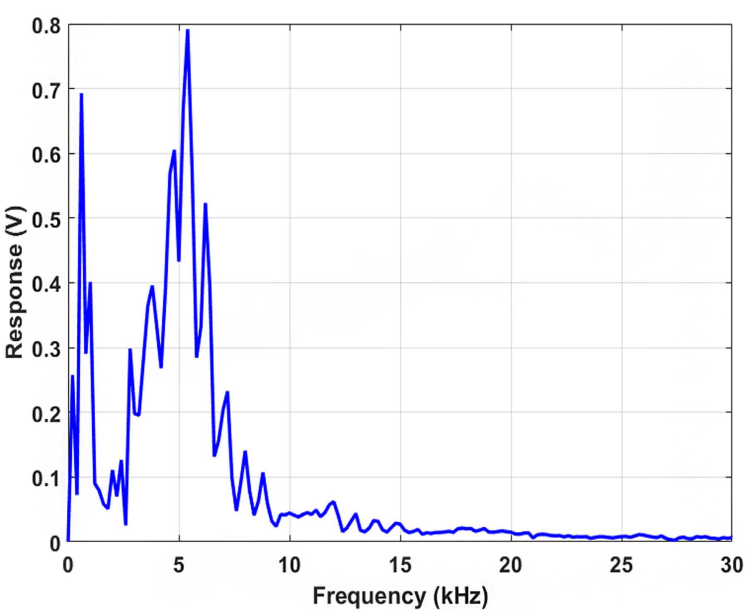

Fig. 9. AE Sensor response in the frequency domain.

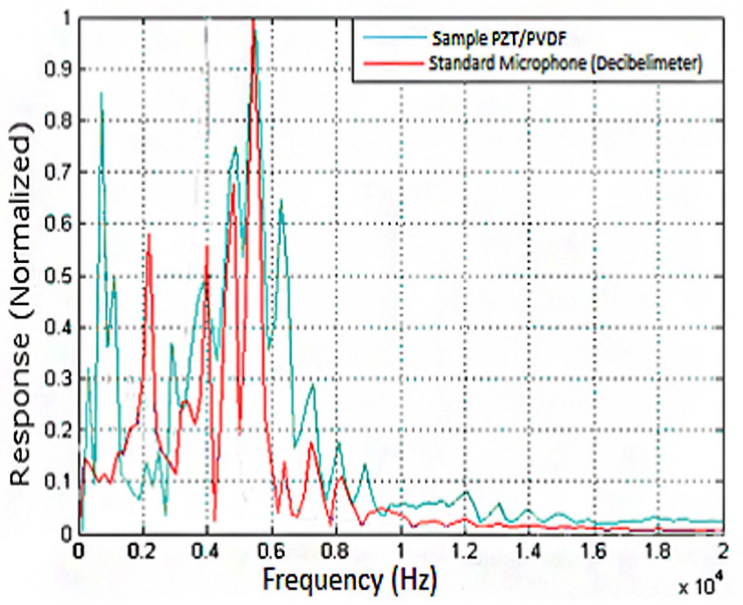

Fig. 10. Normalized response of the sensor for acoustic emission.

noise. Similar results were reported by Or et al. [26] for the $\mathrm{P}(\mathrm{VDF}-\mathrm{TrFE})$ copolymer. The Fourier transform of the signal, shown in Fig. 9, has a maximum amplitude around $5 \mathrm{kHz}$.

To verify the quality and magnitude of the PZT/PVDF $\mathrm{AE}$ sensor, we compared its response to that of a standard microphone in the system shown in Fig. 2. As we can see in Fig. 10, there is good agreement in the responses of the sensors in the frequency range of $2-6 \mathrm{kHz}$.

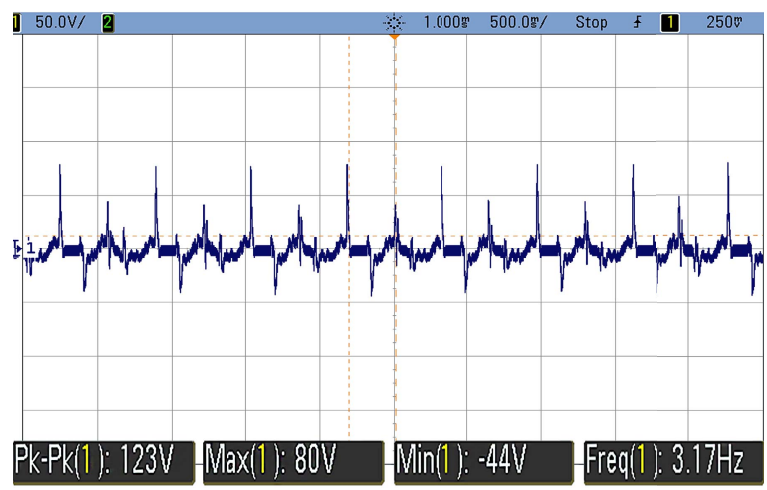

Fig. 11. Composite's response to the deformation produced by the steel roll.

Figure 11 shows the composite's response to the deformation produced by the steel roll. The roll moves forward and backward, thereby generating positive and negative peaks. The composite sample produced a peak signal value of $80 \mathrm{~V}$. To calculate the dissipated power, we connected a resistive load of $100 \mathrm{k} \Omega$ to the sample and we measured an RMS voltage of $3.98 \mathrm{~V}$, which provides $158.5 \mu \mathrm{W}$, which gives $1.6 \mu \mathrm{W} / \mathrm{cm}^{3}$. Zhou et al. [27], using PZT nanowire found $2.4 \mu \mathrm{W} / \mathrm{cm}^{3}$. We used a $100 \mathrm{k} \Omega$ resistor to consider the impedance match with the electrical circuit [28].

\section{CONCLUSIONS}

In this study, we obtained mechanically resistant PZT/PVDF and flexible composite films with mixed connectivity. After the polarization process, we used the composite as both a sensor and actuator. The application of electrical signals with amplitudes in the range of $0-500 \mathrm{~V}$ produced mechanical displacements of the composite in the nanometer range. We observed a very small hysteresis $(0.4 \mathrm{~nm})$ following the application to the composite of an electrical signal with a frequency of $4110 \mathrm{~Hz}$.

With regard to sensing, the composite showed sensitivity in detecting a sudden release of energy by a pencil-lead break $10 \mathrm{~cm}$ away from the sensor. This pencil-lead break test simulates certain structural failures, such as a crack inside a structure. The result obtained by the sensor indicates that it can be used as an acoustic emission sensor.

The results of the energy-harvesting experiment indicate a material that merits further careful study. There is real potential for using the described composite material as a renewable source to generate clean energy for electronic devices and battery charging.

\section{ACKNOWLEDGMENT}

The authors wish to thank F. C. Pereira and J. H. Galeti for helping with the interferometry measurements.

\section{REFERENCES}

[1] A. Thomas, "Functional materials: From hard to soft porous frameworks," Angew. Chem. Int. Ed., vol. 49, no. 45, pp. 8328-8344, 2010.

[2] T. Monetta, A. Acquesta, and F. Bellucci, "Graphene/epoxy coating as multifunctional material for aircraft structures," Aerospace, vol. 2, no. 3, pp. 423-434, 2015. 
[3] E. D. Niri and S. Salamone, "A probabilistic framework for acoustic emission source localization in plate-like structures," Smart Mater. Struct., vol. 21, no. 3, p. 035009, 2012.

[4] K. S. Ramadan, D. Sameoto, and S. Evoy, "A review of piezoelectric polymers as functional materials for electromechanical transducers," Smart Mater. Struct., vol. 23, no. 3, p. 033001, 2014.

[5] G. M. Spinks, L. Liu, G. G. Wallace, and D. Zhou, "Strain response from polypyrrole actuators under load," Adv. Funct. Mater., vol. 12, no. 7, pp. 437-440, 2002

[6] S. Herold and D. Mayer, "Adaptive piezoelectric absorber for active vibration control," Actuators, vol. 5, no. 1, p. 7, 2016.

[7] K.-I. Park et al., "Flexible nanocomposite generator made of $\mathrm{BaTiO}_{3}$ nanoparticles and graphitic carbons," Adv. Mater, vol. 24, no. 22, pp. 2999-3004, 2012

[8] N. Saber et al., "Smart thin-film piezoelectric composite sensors based on high lead zirconate titanate content," Structural Health Monitor. vol. 14, no. 3, pp. 214-227, 2014.

[9] T. Zhai, D. Li, G. Fei, and H. Xia, "Piezoresistive and compression resistance relaxation behavior of water blown carbon nanotube/polyurethane composite foam," Composites A, Appl. Sci. Manuf., vol. 72, pp. 108-114, May 2015.

[10] H. Xiang and L. Wang, "Piezoelectric energy harvester for public roadway: On-site installation and evaluation," Appl. Energy, vol. 174, pp. 101-107, Jul. 2016

[11] A. Toprak and O. Tigli, "Piezoelectric energy harvesting: State-of-the-art and challenges," Appl. Phys. Rev., vol. 1, no. 3, p. 031104, 2014.

[12] A. Delnavaz and J. Voix, "Flexible piezoelectric energy harvesting from jaw movements," Smart Mater. Struct., vol. 23, no. 10, p. 105020, 2014

[13] A. Zelenyak, M. A. Hamstad, and M. G. R. Sause, "Modeling of acoustic emission signal propagation in waveguides," Sensors, vol. 15, no. 5, pp. 11805-11822, 2015.

[14] A. Nair and C. S. Cai, "Acoustic emission monitoring of bridges: Review and case studies," Eng. Struct., vol. 32, no. 6, pp. 1704-1714, 2010.

[15] K. Uchino, "Piezoelectric actuators 2006; Expansion from IT/robotics to ecological/energy applications," J. Electroceram., vol. 20, nos. 3-4, pp. 301-311, 2008.

[16] R. E. Newnham, D. P. Skinner, and L. E. Cross, "Connectivity and piezoelectric-pyroelectric composites," Mater. Res. Bull., vol. 13, no. 5, pp. 525-536, 1978.

[17] W. K. Sakamoto, S. Shibatta-Katesawa, D. H. F. Kanda, S. H. Fernandes, E. Longo, and G. O. Chierice, "Piezoelectric effect in composite polyurethane-ferroelectric ceramics," Phys. Status Solidi A, Appl. Mater. Sci., vol. 172, no. 1, pp. 265-271, 1999.

[18] B. Ploss, W.-Y. Ng, H. L.-W. Chan, B. Ploss, and C.-L. Choy, "Poling study of PZT/P (VDF-TrFE) composites," Composites Sci. Technol., vol. 61, no. 7, pp. 957-962, 2001.

[19] Y. J. Choi et al., "Dielectric and piezoelectric properties of ceramicpolymer composites with 0-3 connectivity type," J. Electroceram. vol. 30 , nos. $1-2$, pp. $30-35,2013$.

[20] N. K. James, D. van den Ende, U. Lafont, S. van der Zwaag, and W. A. Groen, "Piezoelectric and mechanical properties of structured PZT-epoxy composites," J. Mater. Res., vol. 28, no. 4, pp. 635-641, 2013.

[21] Z. Wu, Z. Yang, J. Zhang, and X. Qu, "Fabrication and characterization of the piezoelectric ceramic-Polymer composites," Int. J. Appl. Ceram. Technol., vol. 13, no. 4, pp. 690-696, 2016.

[22] M. Pang et al., "Phase mode-matching demodulation scheme for interferometric fiber-optic sensors," IEEE Photon. Technol. Lett., vol. 19, no. 1, pp. 39-41, Jan. 1, 2007.

[23] X. M. Zhang et al., "Phase modulation with micromachined resonant mirrors for low-coherence fiber-tip pressure sensors," Opt. Exp., vol. 17, pp. 23965-23973, 2009

[24] Q. Guo, G. Z. Cao, and I. Y. Shen, "Measurements of piezoelectric coefficient $d_{33}$ of lead zirconate titanate thin films using a mini force hammer," J. Vibrat. Acoust., vol. 135, no. 1, p. 011003, 2013.

[25] M. G. R. Sause, "Investigation of pencil-lead breaks as acoustic emission sources," J. Acoust. Emission, vol. 29, pp. 184-196, Jan. 2011.

[26] S. W. Or, H. L. W. Chan, and C. L. Choy, "P(VDF-TrFE) copolymer acoustic emission sensors," Sens. Actuators A, Phys., vol. 80, no. 3, pp. 237-241, 2000.

[27] Z. Zhou, H. Tang, and H. A. Sodano, "Scalable synthesis of morphotropic phase boundary lead zirconium titanate nanowires for energy harvesting," Adv. Mater., vol. 26, no. 45, pp. 7547-7554, 2014

[28] H. Roshani, S. Dessouky, S. Dessouky, and A. T. Papagiannakis, "Energy harvesting from asphalt pavement roadways vehicle-induced stresses: A feasibility study," Appl. Energy, vol. 182, pp. 210-218, Nov. 2016.

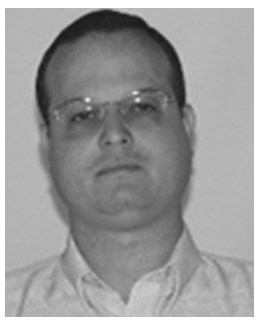

Ricardo Luiz Barros de Freitas received the B.Sc. degree in computer engineering from the School of Engineering of Lins in 2005 and the M.Sc. and Ph.D. degrees in electrical engineering from UNESP-São Paulo State University, Ilha Solteira, Brazil, in 2008 and 2012, respectively. He joined the UNESP Optimization Group, Ilha Solteira with a CNPq PDJ grant (2015), as a Post-Doctoral Researcher. $\mathrm{He}$ has experience in electrical engineering, computer engineering, and biomedical engineering. $\mathrm{He}$ is currently an Adjunct Professor Doctor with the Department of Electrical Engineering and collaborator of the Master's Program in electrical engineering and computing with UNIOESTE-CECE-Campus Foz do Iguaçu. His research interests are knowledge optimization, intelligent materials, piezoelectricity, electronic instrumentation, structured programming, microcontrollers, sensors, hardware, software, and artificial neural networks.

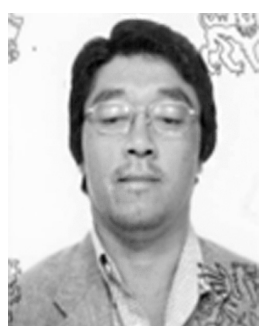

Walter Katsumi Sakamoto received the D.Sc. degree from the Institute of Physics of São Carlos, University of São Paulo, in 1990. In 1999, he joined the University of Wales, Bangor, for his postdoctoral research on piezo and pyroelectric composites, working with Dr. D. K. Das-Gupta. He joined Ilha Solteira at São Paulo State University-UNESP and created the Polymer Group. His current interest is on fabrication and characterization of materials for sensors and energy harvesting. He is a reviewer for some journals.

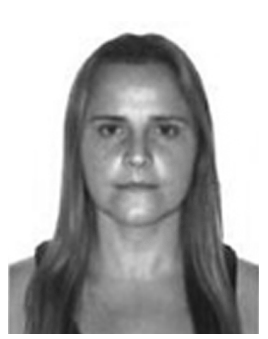

Luciana Paro Scarin Freitas received the Degree in mathematics from the University Center of Norte Paulista in 1999, the bachelor's degree in pedagogy from the Federal University of São Carlos in 2012, and the M.Sc. and Ph.D. degrees in electrical engineering from UNESP-São Paulo State University, Ilha Solteira, Brazil, in 2011 and 2016, respectively. She is currently a Professor with the American Anglo College and a Professor with the Union of the Americas Faculty. She has experience in composites, modeling with emphasis on mathematics, focusing mainly on the following subjects: plantar region, force platform, computer program, podoposturology, and extensometer.

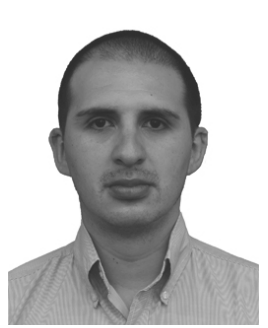

Fabian Castro received the B.S. degree in electronic engineering from the Pedagogical and Technological University of Colombia, Sogamoso, Colombia, in 2011, and the M.S. degree in electrical engineering from UNESP-São Paulo State University, Ilha Solteira, Brazil, in 2016, where he is currently pursuing the $\mathrm{Ph} . \mathrm{D}$. degree in electrical engineering. His main research interests include piezoresistive composites, sensor networks, biomedical devices, and artificial neural networks.

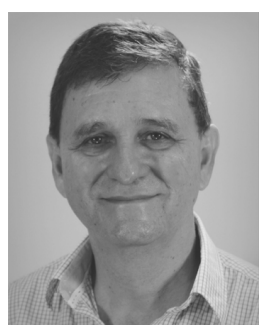

Antonio P. Lima Filho received the Degree in metallurgical engineering from Universidade Federal Fluminense, Volta Redonda, Brazil, in 1985, the M.S. degree in aeronautical and mechanical engineering from the Technological Institute of Aeronautics, São José dos Campos, Brazil, in 1991, and the $\mathrm{Ph} . \mathrm{D}$. degree in materials engineering from the University of Sheffield in 1998. He is currently an Associate Professor with UNESP-São Paulo State University. He has experience in aerospace engineering, with emphasis on materials and processes for aeronautical and aerospace engineering. He focused mainly on the following topics: metal matrix composites, cast metallic strips, and development of product for disabled people. 


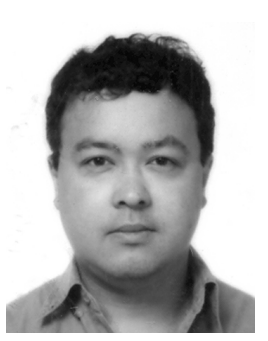

Claudio Kitano received the Diploma degree in electrical engineering from the UNESP-São Paulo State University, São Paulo, Brazil, in 1986, and the master's degree in electronics engineering and the D.Sc. degree in microwave and optoelectronics from the Technological Institute of Aeronautics, São Jose dos Campos, Brazil, in 1993 and 2001, respectively. Since 1987, he has been with the Department of Electrical Engineering, UNESP. His current research interests include optical interferometry, optical fiber sensors, integrated optics, photothermal science, elastic guided waves, acoustic optic, and optical high-voltage sensors.

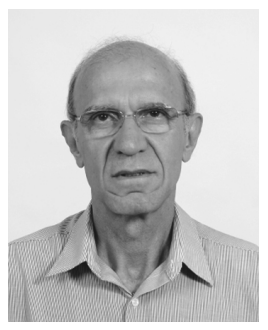

Aparecido Augusto de Carvalho received the B.S. degree in electrical engineering from the University of São Paulo in 1976, the M.S. degree in biomedical engineering from the Federal University of Rio de Janeiro in 1979, and the Ph.D. degree in physics from the University of São Paulo in 1987. He started his career as an Assistant Professor with the Department of Electrical Engineering, São Paulo State University-UNESP, Brazil, in 1980. From 1993 to 1994, he was a Post-Doctoral Scientist with the University of Wisconsin-Madison, investigating a method for measuring of X-ray intensity in the medical diagnostic range by pyroelectric sensors and a method for extending the practical range of conductive polymer sensors for measuring contact force. Since 2005, he has been a Professor. His research interests include biomedical instrumentation, rehabilitation engineering, and functional electrical stimulation. He was a member of the Advisory Committee of the National Council for Scientific and Technological Development-CNPq, Brazil, in the area of electrical and biomedical engineering, from 2008 to 2010. He was the Secretary of the Brazilian Society of Biomedical Engineering in the 2011-2012 biennium. 